\title{
Estruturas secretoras em órgãos vegetativos e florais de Secondatia densiflora A.DC. (Apocynaceae - Apocynoideae - Odontadenieae)
}

MARTINS, F.M. ${ }^{1 *}$; MASCARENHAS, A.A.S.1; MACEDO, T.P. ${ }^{1}$; CUNHA NETO, I.L. ${ }^{1}$

1 Universidade Federal do Recôncavo da Bahia, Centro de Ciências Agrárias, Ambientais e Biológicas, Rua Rui Barbosa 710, 44380-000, Cruz das Almas, BA, Brasil.*fmartins@ufrb.edu.br

RESUMO: A família Apocynaceae é caracterizada por possuir grande diversidade de estruturas secretoras como idioblastos, coléteres, laticíferos e nectários florais. Este estudo teve por objetivo caracterizar anatomicamente as estruturas secretoras nos órgãos vegetativos e reprodutivos de Secondatia densiflora e identificar as principais classes de compostos químicos nos idioblastos e na secreção dos coléteres vegetativos. Os idioblastos estão distribuídos por todos os órgãos aéreos da planta possuindo conteúdo na maioria das vezes denso e fortemente corado pela safranina. Alguns idioblastos apresentam secreção de aspecto granulado. Os testes histoquímicos evidenciaram apenas compostos fenólicos. Os laticíferos são do tipo anastomosado podendo ser observados em todos os órgãos estudados e identificados pelo conteúdo diferenciado e, em alguns casos, pela presença de paredes celulares mais espessas que as paredes das células parenquimáticas. O látex tem cor branca e aspecto leitoso, sendo extravasado logo que a planta é lesionada. Os coléteres vegetativos são do tipo padrão, formados por uma porção alongada que se afina em direção à extremidade. A epiderme secretora em paliçada delimita uma região parenquimática e o curto pedúnculo é coberto por epiderme não secretora de formato retangular. Todo coléter é recoberto por cutícula fina. A mucilagem é constatada tanto no interior das células secretoras quanto no meio extracelular pelo vermelho de rutênio e pela reação PAS. Os nectários florais têm origem receptacular, possuem uma epiderme que reveste toda estrutura, parênquima nectarífero, e feixes vasculares; são fundidos na base e livres na região apical constituindo cinco unidades distintas.

Palavras-chave: idioblasto, coléter, laticífero, nectário floral

ABSTRACT: Secretory structures in vegetative and floral organs of Secondatia densiflora A.DC. (Apocynaceae - Apocynoideae - Odontadenieae). The family Apocynaceae is characterized for showing a wide variety of secretory structures such as idioblasts, colleters, laticiferous glands and floral nectaries. The present study aimed to anatomically characterize the secretory structures in vegetative and reproductive organs of Secondatia densiflora and to identify the major classes of chemical compounds in idioblasts and in the secretion of vegetative colleters. Idioblasts are distributed all over the aerial organs of the plant and their content is usually dense and strongly stained with safranin. Some idioblasts have secretion of granulated aspect. Histochemical tests evidenced phenolic compounds only. Laticiferous glands are of the anastomosed type and can be seen in all the studied organs and identified by their distinct content and, in some cases, by the presence of cell walls that are thicker than those of parenchyma cells. Latex is white, milky and leaks as the plant is injured. Vegetative colleters are of the standard type and formed of an elongated portion that becomes thinner towards the end. The secretory palisade epidermis delimits a parenchymatic region, while the short peduncle is covered by rectangular non-secretory epidermis. A thin cuticle covers the entire colleter. Mucilage is detected both inside the secretory cells and in the extracellular medium by ruthenium red staining and PAS reaction. Floral nectaries have receptacular origin and epidermis covering their entire structure, nectariferous parenchyma, and vascular bundles; they are fused at their bases but have free apical region, forming five distinct units.

Key words: idioblast, colleter, laticifer, floral nectary

Recebido para publicação em 03/05/2011

Aceito para publicação em 25/06/2012

Rev. Bras. PI. Med., Botucatu, v.15, n.1, p.13-24, 2013. 


\section{INTRODUÇÃO}

Apocynaceae sensu lato é uma das maiores e mais representativas famílias de Angiospermas, contando com cerca de 300 gêneros e 4000 espécies (Judd et al., 2002). No Brasil está representada por cerca de 90 gêneros e aproximadamente 850 espécies (Souza \& Lorenzi, 2005), distribuídas em diversas formações vegetacionais.

Os representantes dessa família destacamse por sua importância na medicina popular (Marimuthu, 1988; Oliveira \& Akissue, 1989), abrangendo espécies ricas em alcalóides e compostos iridóides (Bruneton, 1999). Dentre as espécies de valor medicinal, podem ser citadas Strophanthus hispidus que produz glicosídeos cardiogênicos, Catharanthus roseus que possui alcalóides anticarcinogênicos e Rauvolfia serpentina cujos alcalóides têm efeito hipotensor e sedativo (Oliveira \& Akissue, 1989; Bruneton, 1999). Espécies tóxicas e venenosas também são encontradas como, por exemplo, Asclepias curassavica que possui látex composto por glicosídeos digitálicos (Riet-Correa et al., 1993) e Nerium oleander, a popular espirradeira (Joly, 1977).

Muitas estruturas secretoras estão envolvidas na produção de diferentes compostos do metabolismo secundário nas espécies desta família, podendo ser citados: tricomas, idioblastos, laticíferos, coléteres, cavidades, epiderme da cabeça dos estiletes, nectários e osmóforos (Solereder, 1908; Woodson \& Moore, 1938; Metcalfe \& Chalk, 1950; Fallen, 1986; Thomas, 1991; Galleto, 1997; Torres \& Galleto, 1998; Lin \& Bernardello, 1999). Para as Apocynaceae da flora brasileira, estas estruturas secretoras foram anatomicamente caracterizadas em cerca de 50 espécies (Appezzato-da-Glória \& Estelita, 2000; Rio et al., 2002, 2005; Simões 2004; Demarco 2005; Demarco et al. 2006; Simões et al. 2006, 2007; Gomes et al., 2008; Aguiar et al. 2009; Martins et al. 2010; Martins 2012).

A presente investigação tem por objetivo caracterizar anatomicamente as estruturas secretoras localizadas em órgãos vegetativos e reprodutivos de Secondatia densiflora A.DC. e identificar as principais classes de compostos químicos presentes nos idioblastos e na secreção dos coléteres vegetativos.

\section{MATERIAL E MÉTODO}

O material de estudo foi coletado em três áreas de cerrado do Estado de São Paulo: Reserva Biológica e Estação Experimental de Mogi Guaçu, Estação Ecológica e Experimental de Itirapina e Horto Botânico de Bauru. Material testemunha proveniente de cinco indivíduos foi incorporado ao Herbário da Universidade Estadual de Campinas,
UEC 147876, 147877, 147878, 147879, 147880.

Ramos vegetativos com ápices caulinares, primórdios foliares, folhas completamente expandidas, inflorescências portadoras de botões florais com $5 \mathrm{~mm}, 8 \mathrm{~mm}$ e $10 \mathrm{~mm}$ de comprimento e flores em antese com $12 \mathrm{~mm}$ de comprimento foram coletados. A coleta foi realizada com lâmina aquecida para preservar a secreção do laticífero. O material foi fixado em FAA (formalina, ácido acético, álcool etílico 50\%, 1:1:18 v/v) por 24 horas (Johansen, 1940), FNT (formalina neutra tamponada; tampão fosfato, formalina, 9:1 v/v) por 48 horas (Lillie, 1948 in Clark, 1973) e SFF (solução de sulfato ferroso, formalina, 9:1 v/v) por 48 horas (Johansen, 1940). Todo o material foi submetido a vácuo em dessecador durante o processo de fixação e depois transferido para álcool etílico $70 \%$.

As peças foram isoladas e transferidas para álcool butílico terciário $70 \%$, onde permaneceram por aproximadamente sete dias, desidratadas em série butílica e incluídas em parafina histológica (Johansen, 1940). Cortes seriados transversais e longitudinais com espessura de aproximadamente $10 \mu \mathrm{m}$ foram realizadas com uso de micrótomo rotativo. Os cortes foram corados com safranina alcoólica 1,5\% e azul de astra aquoso 1\% (Gerlarch, 1969) e as lâminas permanentes montadas em resina sintética (Permount/Fisher).

Testes histoquímicos foram realizados para identificar as principais classes de compostos químicos na secreção dos idioblastos. Os tratamentos foram: ácido tânico/cloreto férrico III para mucilagem (Pizzolato \& Lillie, 1973; Pizzolato, 1977); reação PAS (pararosalina $\mathrm{Cl} 42510$ ) para polissacarídeos totais (Periodic-Acid-Schiff's reaction; McManus, 1948); preto de amido $\mathrm{B}$ ( $\mathrm{Cl} 20470)$ para proteínas (Fisher, 1968); preto de Sudão B (Cl 26150) para lipídios totais (Pearse, 1985); azul do Nilo (Cl 51180) para lipídios ácidos e neutros (Cain, 1947); cloreto férrico III para compostos fenólicos (Johansen, 1940) e reagente de Wagner para alcalóides (Furr \& Mahlberg, 1981). Os compostos fenólicos também foram evidenciados pelo SFF.

O controle dos testes para substâncias lipofílicas foi realizado com solução extrativa composta por metanol/clorofórmio/água/ $\mathrm{HCl}$ (33:66:4:1 v/v, High 1948). As amostras foram submetidas a essa solução por um período de 48 horas em temperatura ambiente, logo em seguida fixadas em FAA ou em FNT e submetidas aos mesmos tratamentos das demais peças. Os controles para os testes de substâncias hidrofílicas seguem as recomendações metodológicas, com supressão do tratamento pelo cloreto férrico (Pizzolato, 1977) e do tratamento com ácido periódico e tetrahidreto boreto de sódio (McManus, 1948). 
Para evidenciar a presença da mucilagem na secreção dos coléteres, secções de material fixado em FAA foram coradas com vermelho de rutênio (Gregory \& Baas, 1989) e submetidas à reação PAS (McManus, 1948). A descrição dos coléteres foi realizada no segundo nó, pois todos os coléteres estão desenvolvidos nesse estágio. A classificação dos coléteres está de acordo com Lersten (1974).

As fotomicrografias foram obtidas em microscópio Olympus BX51 equipado com câmera digital Olympus E330. As escalas das figuras foram obtidas através da projeção de uma lâmina micrométrica fotografada/digitalizada nas mesmas condições ópticas das demais ilustrações.

\section{RESULTADO}

Os idioblastos de S. densiflora estão distribuídos por todos os órgãos aéreos da planta (Figuras 1 a 35). Nas folhas jovens, ocorrem no parênquima fundamental e associados ao floema da nervura mediana. No caule primário e secundário, estão presentes no córtex e na medula (Figuras 5 e 6). Nos botões florais, os idioblastos são encontrados em todas as peças. Eles ocorrem no parênquima das sépalas, pétalas, estames, nectários e carpelos (Figuras 29 a 32). Os idioblastos também são observados no parênquima dos coléteres foliares (Figuras 24, 27 e 28) e florais. Uma hipoderme secretora com conteúdo de aspecto denso semelhante ao dos idioblastos é observada na superfície abaxial da folha jovem (Figuras $1 \mathrm{e}$ 2 ); entretanto, tal estrutura não está presente no mesofilo das folhas adultas (Figuras 3 e 4). No caule, a hipoderme permanece no estádio secundário, sendo interrompida apenas pela presença das câmaras subestomáticas (Figuras 5 e 6).

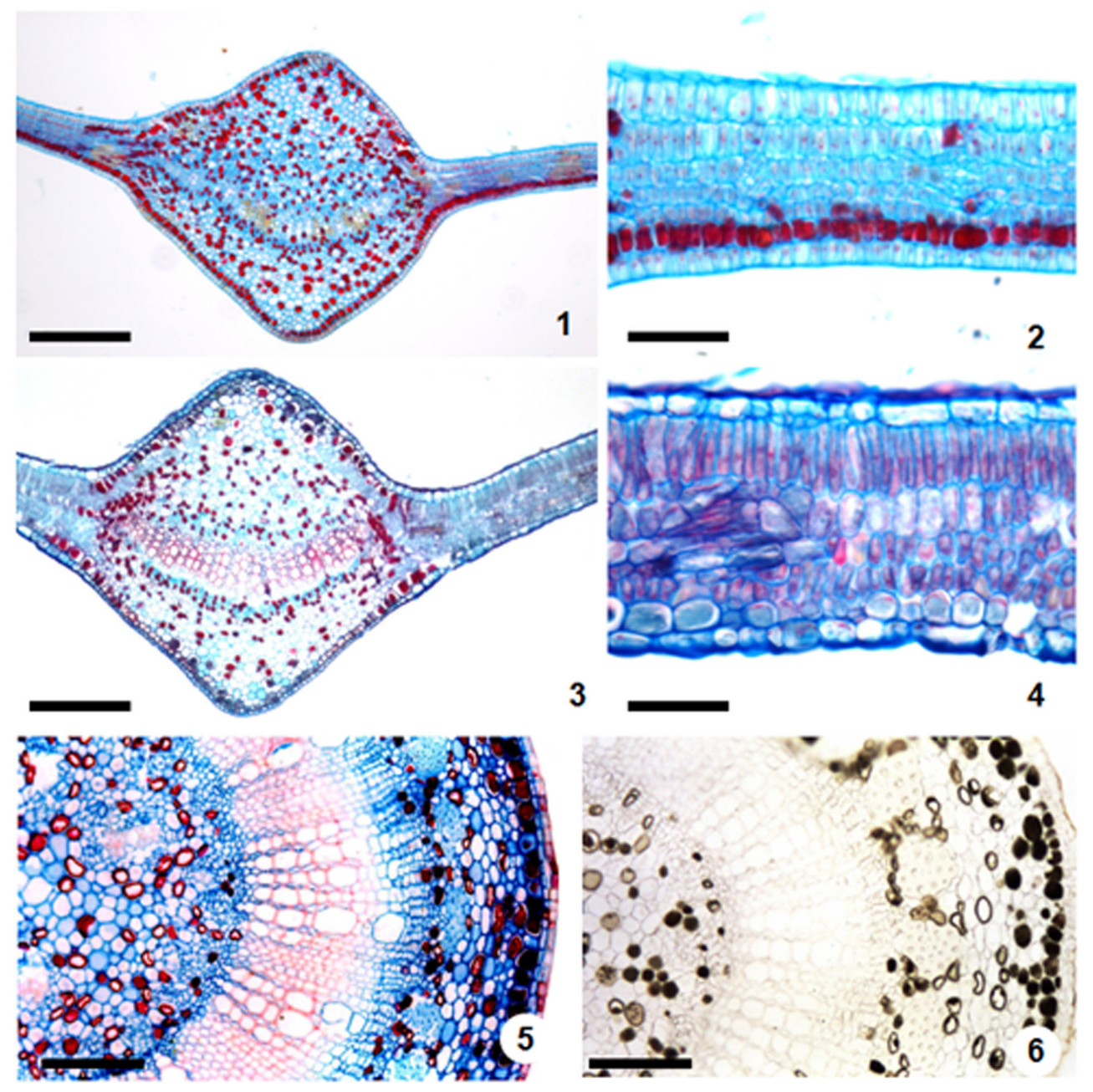

FIGURAS 1-6. Secções transversais de órgãos vegetativos de Secondatia densiflora. 1. Nervura mediana da folha jovem. 2. Idioblastos em posição subepidérmica na folha jovem. 3. Nervura mediana da folha adulta. 4. Folha adulta sem idioblastos em posição subepidérmica. 5. Caule em estágio secundário, notar idioblastos na região medular e

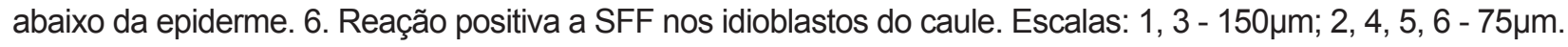


O conteúdo na maioria das vezes é denso (Figura 8) e fortemente corado pela safranina. Alguns idioblastos apresentam secreção de aspecto granulado (Figura 7). Não há diferença na distribuição entre os idioblastos de conteúdo granulado e denso. Os testes histoquímicos evidenciaram apenas compostos fenólicos (Figuras 9 e 10).

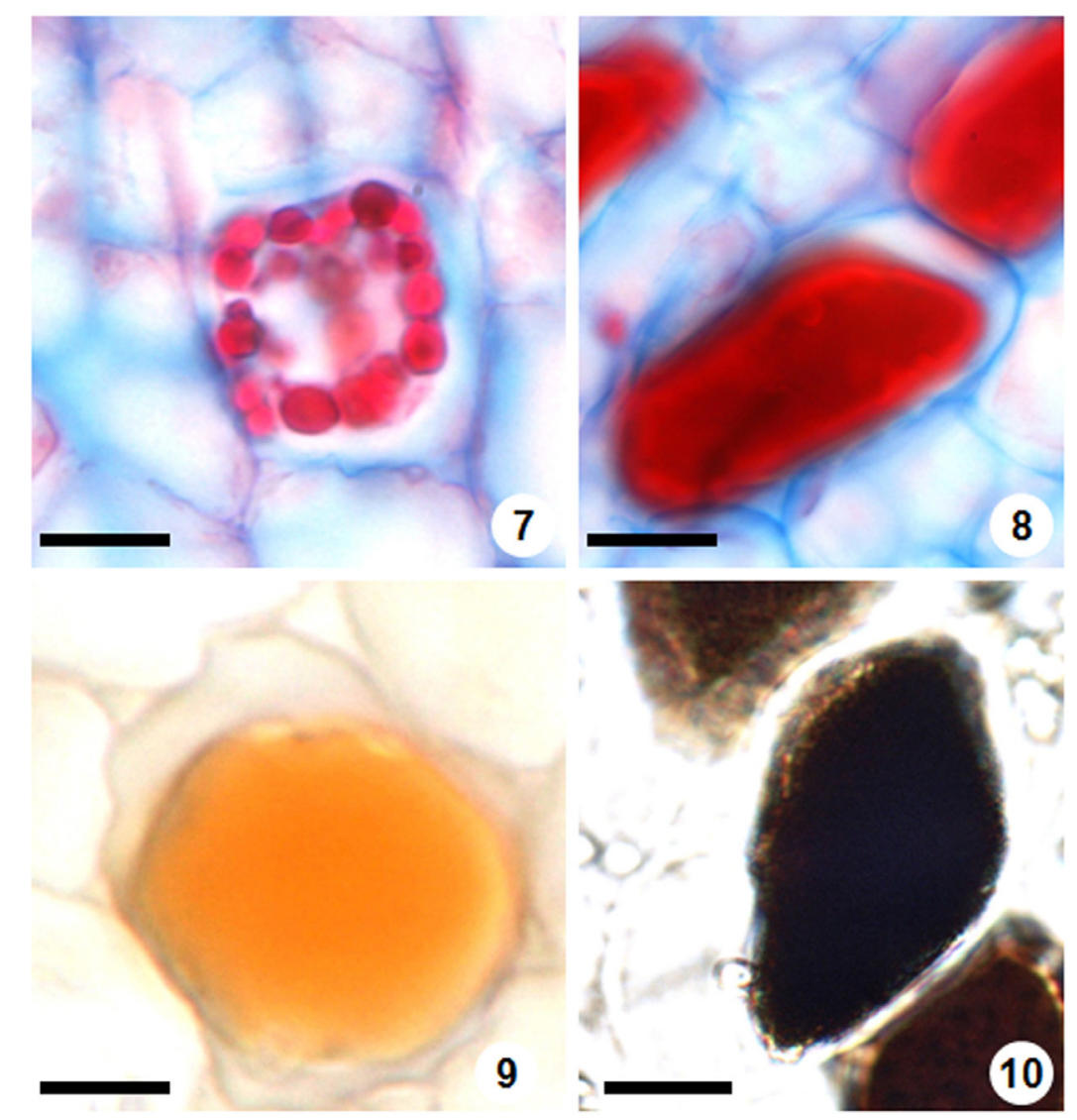

FIGURAS 7-10. Idioblastos no ápice caulinar de Secondatia densiflora. 7. Idioblastos com secreção de aspecto granulado. 8. Idioblasto com secreção densa. 9. Coloração de um idioblasto fixado em FNT. 10. Reação positiva ao teste com cloreto férrico. Escalas: $15 \mu \mathrm{m}$.

Os laticíferos são do tipo anastomosado (Figuras 11 a 13) podendo ser observados em todos os órgãos estudados. Eles estão presentes na lâmina foliar e pecíolo, localizados próximos ao feixe vascular. No caule, são observados tanto na região cortical como na medular. Nos botões florais, estão presentes em todas as peças (Figuras 32). Eles ocorrem no receptáculo floral, dispersos entre os feixes vasculares, no parênquima das sépalas, pétalas, nectário floral e carpelos.

Laticíferos podem ser facilmente identificados pelo seu conteúdo diferenciado e, em alguns casos, pela presença de paredes celulares mais espessas que as paredes das células parenquimáticas (Figuras 13 e 14). O diâmetro é variado e os laticíferos de maior calibre são observados logo abaixo do ápice vegetativo (Figura 11) e na medula do caule (Figura 12). A secreção apresenta aspecto denso sendo fortemente corada pela safranina, evidenciando a natureza acidófila
(Figuras 12 a 13). O látex tem cor branca e aspecto leitoso, sendo extravasado logo que a planta é lesionada.

Os coléteres vegetativos são encontrados nos estágios iniciais do desenvolvimento no ápice caulinar (Figuras 15 a 22). Em cada nó, 18-19 coléteres são observados, ocorrendo 9-10 coléteres por primórdio (Figura 15). Por primórdio, um coléter tem origem axilar e os demais têm origem peciolar (Figuras 15 a 22). O número de coléteres marginais varia entre indivíduos. Ocorre também uma variação no tamanho dos coléteres; o axilar atinge no máximo $400 \mu \mathrm{m}$ e os marginais variam entre $360 \mu \mathrm{m}$ e $1300 \mu \mathrm{m}$ de comprimento.

Os primeiros coléteres a se desenvolverem são os intrapeciolares, incluindo o axilar. Outros seis coléteres surgem a partir da porção interna da estípula, ocupando posição interpeciolar (Figura 19). Os últimos a se formarem também ocupam posição interpeciolar, entretanto estão localizados 


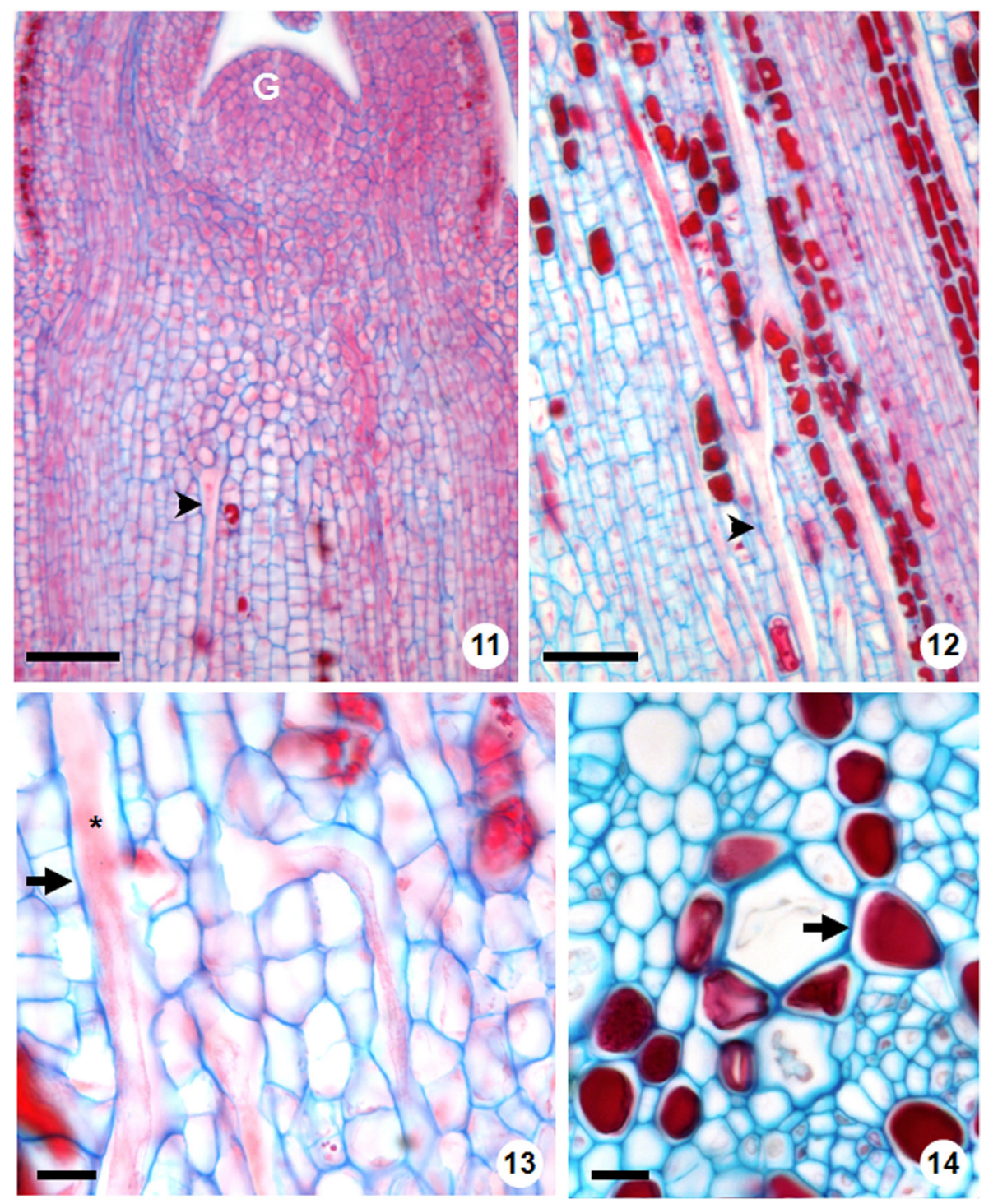

Figuras 11-14. Secções longitudinais (11-13) e transversal (14) do ápice caulinar de Secondatia densiflora. 11. Vista geral do ápice caulinar. 12. Laticíferos na medula do caule. 13. Detalhe do laticífero (seta), notar secreção (asterisco) corada pela safranina. 14. Laticífero com parede celular mais espessa (seta) que as paredes das células parenquimáticas. Legenda: Cabeça de seta - laticífero; G - gema. Escalas: 11- $150 \mu \mathrm{m} ; 12$ - $80 \mu \mathrm{m}$; $13,14-25 \mu \mathrm{m}$.

mais externamente ao caule. Todos os coléteres são destituídos de vascularização.

Os coléteres são do tipo padrão, formados por uma porção alongada que se afina em direção à extremidade. A epiderme secretora em paliçada delimita um núcleo parenquimático e o curto pedúnculo é coberto por epiderme não secretora de formato retangular (Figuras 23 e 24). Todo coléter é recoberto por uma parede periclinal externa fina. A secreção é observada no interior das células corada pela safranina e no meio externo corada pelo azul de astra (Figuras 23 a 26). A mucilagem é constatada tanto no interior das células secretoras quanto no meio extracelular pelo vermelho de rutênio e pela reação PAS (Figuras 27 e 28).

Os nectários florais são fundidos na base e livres na região apical constituindo assim cinco unidades distintas (Figura 29 a 34). Eles têm origem receptacular, possuem epiderme que reveste toda estrutura, parênquima nectarífero e feixes vasculares (Figura 35). Os idioblastos estão no parênquima do nectário ocupando principalmente posição central (Figura 34); nas demais estruturas estudadas, ocupam posição subepidérmica. Na porção apical dos nectários, os estômatos são observados em maior concentração e provavelmente estão envolvidos na secreção do néctar. As células parenquimáticas subepidérmicas apresentam protoplasto denso e fortemente corado pela safranina, que pode indicar a atividade secretora dessas células. 


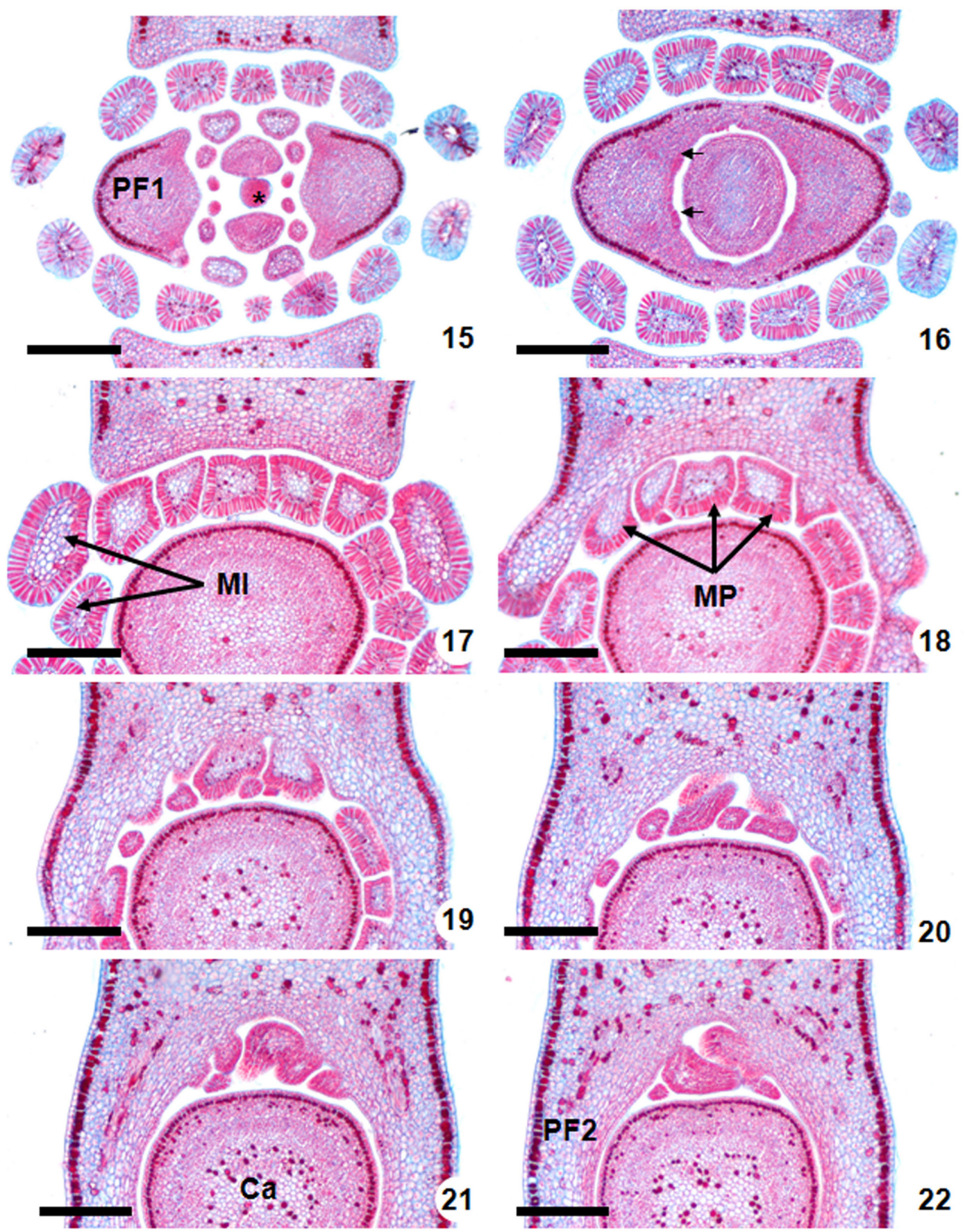

FIGURAS 15-22. Secções transversais do ápice caulinar de Secondatia densiflora. 15. Meristema apical (asterisco) do caule. 16. Primeiro primórdio foliar evidenciando o surgimento dos coléteres intrapeciolares (setas). 17-22. Coléteres axilares, coléteres marginais peciolares (MP) e coléteres marginais interpeciolares (MI) no segundo primórdio foliar (PF2). Legenda: Ca - caule; PF1 - primeiro primórdio foliar. Escalas: $85 \mu \mathrm{m}$.

\section{DISCUSSÃO}

\section{Idioblastos}

Os idioblastos estão presentes em todos os órgãos estudados de Secondatia densiflora. Eles são observados ocupando posição hipodérmica nos órgãos adultos de Forsteronia glabrescens (Rio et al., 2005), Mandevilla pentlandiana (Galetto, 1997) e
Mandevilla pohliana (Appezzato-da-Glória \& EstelitaTexeira, 1992). Em S. densiflora, a formação de uma hipoderme secretora ocorre apenas no caule, pois na folha adulta os idioblastos não estão distribuídos de forma contínua como no órgão jovem. Castro \& Demarco (2008) afirmam que células secretoras distribuídas de forma contínua em órgãos jovens que mantêm a mesma distribuição em órgãos adultos 


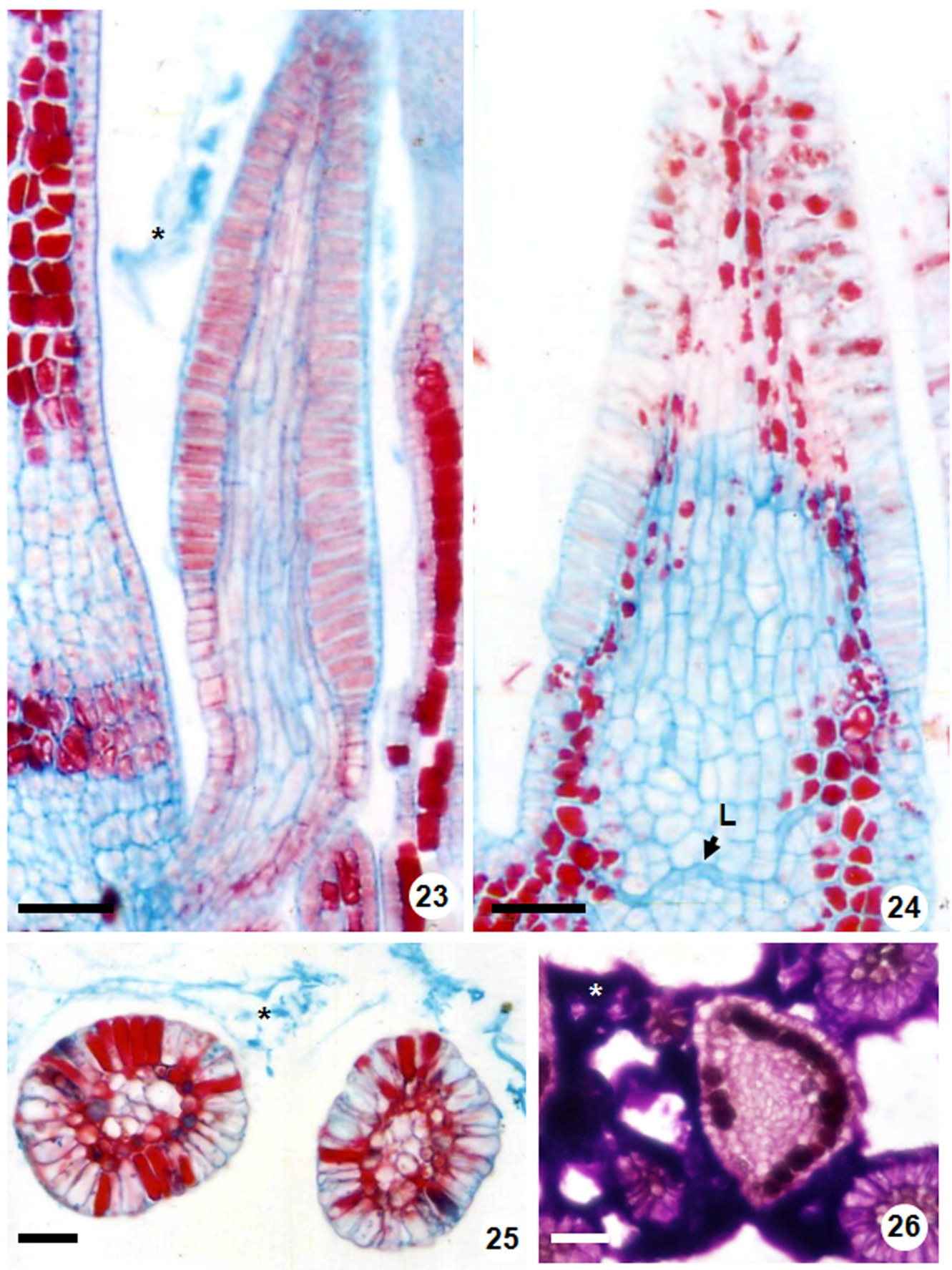

FIGURAS 23-26. Secções longitudinais (23-24) e transversais (25-26) dos coléteres vegetativos de Secondatia densiflora. 23. Coléter axilar; secreção nas células epidérmicas e no meio extracelular (asterisco). 24. Coléter marginal interpeciolar em fase pós-secretora; notar laticífero (seta). 25. Coléteres marginais; secreção evidenciada pelo azul de astra. 26. Polissacarídeos evidenciados na secreção (asterisco) pela reação PAS. Escalas: $50 \mu \mathrm{m}$.

constituem uma epiderme ou hipoderme secretora. Idioblastos ocorrem dispersos no parênquima da folha e caule em Forsteronia australis, F. pubescens, F. thyrsoidea (Rio et al., 2005), Mandevilla illustris e M. velutina (Appezzato-da-Glória \& Estelita, 2000). Eles são encontrados no parênquima dos coléteres vegetativos de Forsteronia glabrescens, F. pubescens, F. thyrsoidea (Rio et al., 2005), Mandevilla illustris,
M. velutina (Appezzato-da-Glória \& Estelita, 2000) e no parênquima dos coléteres florais de Mandevilla pycnantha, Macrosiphonia longiflora e Mesechites mansoana (Simões et al., 2006).

Alguns autores identificaram compostos fenólicos nos idioblastos (Appezzato-da-Glória \& Estelita, 2000; Rio et al,. 2005). Em S. densiflora, a presença de compostos fenólicos foi comprovada 


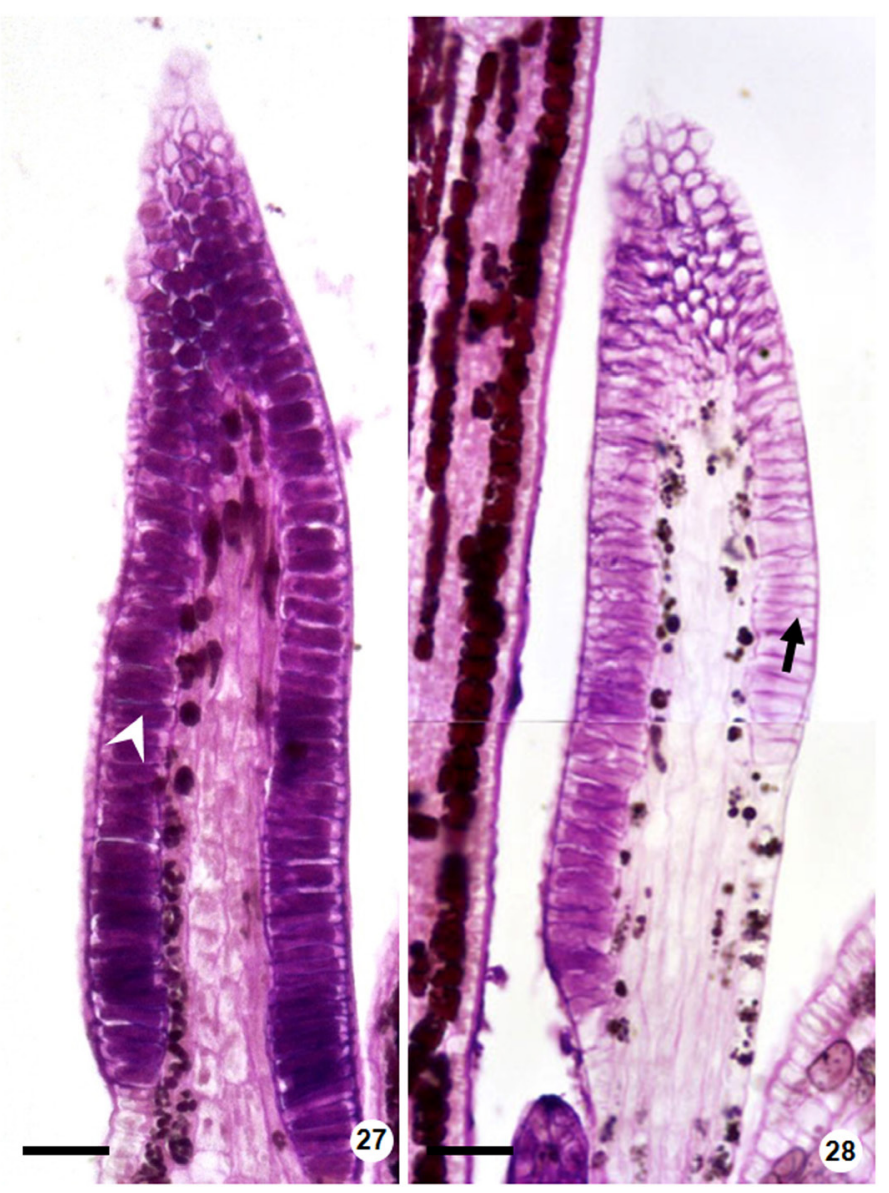

FIGURAS 27-28. Secções longitudinais dos coléteres vegetativos de Secondatia densiflora submetidos à reação PAS. 27. Coléter com células epidérmicas em fase pré-secretora no segundo nó. 28. Coléter em fase pós-secretora no terceiro nó. Escalas: $50 \mu \mathrm{m}$.

pelo SFF e pela reação positiva ao cloreto férrico; além disso, outra evidência da presença desses compostos foi a forte coloração pela safranina. Segundo Gardner (1975), precipitados intracelulares aparecem após a aplicação de corantes básicos como a safranina. A presença desses compostos fenólicos pode estar relacionada à defesa da planta contra o ataque de herbívoros e o crescimento de fungos, pois são substâncias adstringentes e tóxicas (Bruneton, 1999; Simões et al., 2004). Sugere-se que as células secretoras de compostos fenólicos localizadas na corola possam desempenhar a função de guias de néctar para polinizadores pela sua capacidade de refletir raios ultravioleta (Thompson et al., 1972; Kay et al., 1981)

\section{Laticíferos}

Os laticíferos estão presentes em diversas famílias de angiospermas, entre elas Apocynaceae (Metcalfe \& Chalk, 1983). Muitas dessas famílias não apresentam relações taxonômicas, o que sugere que a capacidade de produzir látex surgiu mais de uma vez ao longo da evolução desses grupos (Fahn, 1979). São estruturas constantes em Apocynaceae e ocorrem em órgãos vegetativos e reprodutivos (Wilson \& Mahlberg, 1978; Thomas \& Dave, 1989; Rio et al., 2005; Valente \& Costa, 2005).

Eles foram observados em todos os órgãos estudados de $S$. densiflora. Laticíferos já foram encontrados no mesofilo foliar de Allamanda neriifolia, Thevetia peruviana, Vinca minor (Fjell, 1983), Mateleia maritima (Valente, 1996) e espécies de Forsteronia (Rio et al., 2005); no parênquima cortical e medular do caule de Mandevilla pohliana (Appezzato-da-Glória \& Estelita-Texeira, 1992), Mandevilla illustris e M. velutina (Appezzatoda-Glória \& Estelita, 1997) e no receptáculo floral, verticilos estéreis e carpelos de Marsdenia Ioniceroides (Valente \& Costa, 2005).

Segundo Fahn (1979), os laticíferos podem ser formados por uma única célula sendo assim considerados não articulados ou formados por uma fileira de células sendo denominados articulados. Os laticíferos não articulados têm origem a partir de uma única célula que apresenta crescimento intrusivo através de espaços intercelulares por todos os tecidos da planta (Mahlberg, 1993).

A maioria dos laticíferos de Apocynaceae 


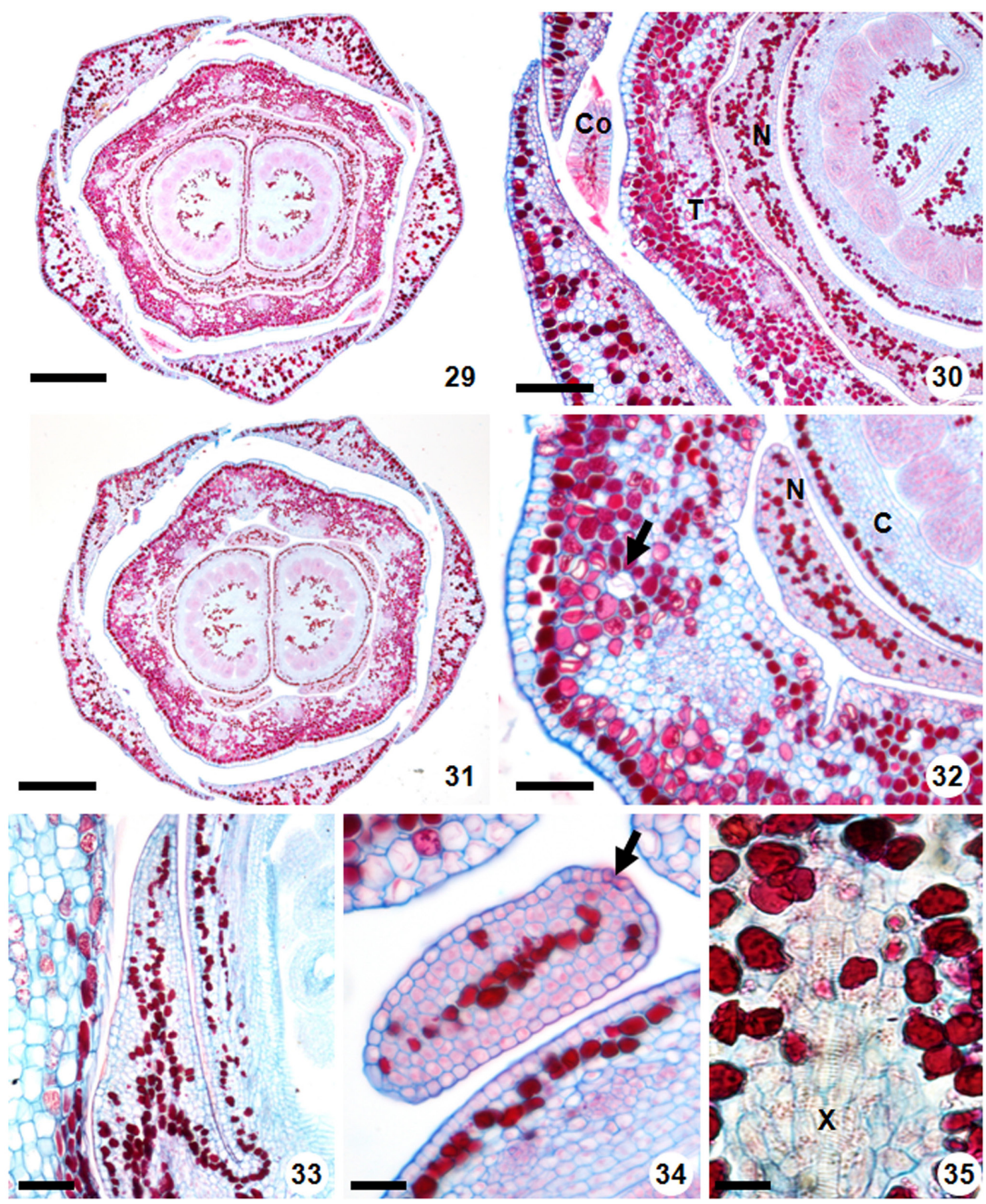

FIGURAS 29-35. Secções transversais (29-32,34) e longitudinais (33-35) do botão floral de Secondatia densiflora. 29 e 31. Vista geral do botão floral. 30. Detalhe do nectário $(\mathrm{N})$ e do coléter calicinal (Co) e secreção no meio externo. 32. Detalhe do nectário floral e do laticífero (seta). 33. Nectário e idioblasto. 34. Detalhe do nectário, notar estômato (seta) e idioblastos. 35. Vascularização do parênquima nectarífero. Legenda: C-carpelo; T-tubo da corola; X-xilema. Escalas: $50 \mu \mathrm{m}$.

é descrita como do tipo não-articulado (Mahlberg, 1963; Wilson \& Malhberg, 1978; Inamdar et al., 1988; Appezzato-da-Glória \& Estelita, 1997). Existe grande divergência quando ao tipo e desenvolvimento dos laticíferos descritos para as espécies desta família. Demarco et al. (2006) afirmaram que os laticíferos de Aspidosperma australe e Blepharodon bicuspidatum são articulados após análise cuidadosa. Segundo eles, este tipo de laticífero tem rápida dissolução da parede terminal, o que pode levar a conclusões equivocadas. Um exemplo desse problema ocorre na divergência entre Mahlberg (1963) e Milanez (1977) em relação aos laticíferos de Nerium oleander. O primeiro autor afirmou que eles 
são do tipo não-articulado, já o segundo do tipo articulado. Há casos em que laticíferos articulados e não-articulados ocorrem na mesma espécie, tal como em Stapelia bella (Wilson \& Maxam, 1987). Laticíferos articulados também foram observados em Vinca sardoa (Sacchetti et al., 1999) e Mandevilla atroviolacea (Lopes, 2007). O estudo dos laticíferos em órgãos adultos não possibilita determinar a origem e, por isso, é necessário que esse tipo de investigação seja realizado em regiões meristemáticas. Mesmo com a análise das regiões meristemáticas de vários indivíduos, não foi possível determinar a origem dos laticíferos de S. densiflora. Talvez a ampliação do número de indivíduos seja necessária para tipificar os laticíferos desta espécie.

Em S. densiflora, os laticíferos apresentaram paredes celulares finas e raramente espessadas, 0 que está de acordo com Mahlberg (1993), que afirmou que as paredes dos laticíferos podem ser muito grossas ou tão finas quanto a parede das células parenquimáticas. A parede é sempre primária e pode possuir substâncias que selam o sistema de laticíferos dos demais tecidos (Fahn, 1990).

Muitas funções já foram atribuídas aos laticíferos. Devido à sua distribuição pelo corpo da planta, ele foi comparado ao tecido sanguíneo dos animais. Por estar próximo ao floema, acreditavase que ele desempenhava a função de auxiliar na translocação de assimilados. Posteriormente, atribuíram a ele a função de reserva nutritiva para planta. Entretanto, foi provado que o material presente no interior do laticífero não era mobilizado em condições desfavoráveis. Atualmente, sabe-se que ele é uma estrutura secretora e que produz várias substâncias que não são reutilizadas no metabolismo primário da planta. Provavelmente, os laticíferos selem ferimentos e protejam as plantas contra o ataque de herbívoros e microorganismos (Fahn, 1979).

\section{Coléteres}

Coléteres vegetativos são amplamente descritos para Apocynaceae (Thomas, 1991; Endress \& Bruyns, 2000). Em S. densiflora, ocorrem de 9 a 10 por primórdio foliar; essa variação é pequena e pode ser observada em outras espécies da família. Segundo Thomas (1991), o número de coléteres de uma mesma espécie pode variar com a distribuição geográfica.O coléter do ápice vegetativo do tipo padrão de $S$. densiflora está presente também em Odontadenia lutea (Martins, 2012), ambos os gêneros da tribo Odontadenieae.O coléter padrão ocorre amplamente em gêneros de outras tribos, tais como Prestonia (Rio et al., 2002) da tribo Echiteae, Forsteronia (Rio et al., 2005) e Mandevilla (Apezzato-da-Glória \& Estelita, 2000) da Mesechiteae. Os coléteres de S. densiflora não apresentaram vascularização, entretanto, há relatos de tecido vascular em coléteres foliares. Martins et al. (2010) descreveram a presença de xilema no coléter marginal distal (interpeciolar) de Temnadenia violacea. Appezzato-da-Glória \& Estelita (2000) observaram vascularização nos coléteres interpeciolares de Mandevilla. Rio et al. (2002) relataram vascularização nos coléteres marginais de Prestonia coalita. Segundo Demarco (2005), a presença de tecido vascular pode variar até mesmo entre os diferentes tipos de coléteres encontrados nos órgãos vegetativos. Os coléteres calicinais de $S$. densiflora foram descritos por Simões et al. (2006) e, por esse motivo, não fizeram parte desse estudo.

\section{Nectários}

Os nectários de S. densiflora são semelhantes aos de outras espécies de Apocynoideae, apresentando-se unidos na base e lobados no ápice. Em um dos primeiros estudos realizados, Woodson \& Moore (1938) descreveram os nectários florais de Apocynaceae como sendo uma estrutura anelar contínua. Trabalhos mais recentes realizados por Galetto (1997), Torres \& Galetto (1998) e Lin \& Bernardello (1999) evidenciaram a ocorrência de nectários contínuos na porção basal, mas que se partem formando até cinco lobos na porção apical. Sakane \& Shepherd (1986) utilizaram a morfologia do nectário para identificar espécies de Allamanda, citando a ocorrência de um disco carnoso que pode ser liso, aneliforme ou lobado. Simões (2004) descreveu a ocorrência de nectários bilobados em Mandevilla tenuifolia.

Outra questão divergente é quanto à origem dos nectários, Woodson \& Moore (1938) afirmaram que a natureza do nectário é carpelar. Rao \& Ganguli (1963) contestaram estes autores e afirmaram a origem receptacular dos nectários; entretanto, sugeriram que nectários carpelares podem ocorrer em um pequeno grupo de Apocináceas. Fahn (1979) mencionou que a posição e a vascularização dos nectários sugerem origem carpelar para Vinca rosea (Apocynaceae). Galetto (1997) e Lin \& Bernardello (1999) afirmaram que estes nectários têm origem receptacular em espécies de Mandevilla e em Aspidosperma quebracho-blaco, respectivamente. Apesar de ambos apontarem origem receptacular, o nectário é inconspícuo e não vascularizado em $A$. quebracho-blaco, grande e vascularizado por xilema e floema nas espécies de Mandevilla.

A avaliação anatômica das estruturas secretoras de $S$. densiflora foi importante para a caracterização da espécie e revelou que as características observadas estão de acordo com os relatos referidos na literatura para a

Rev. Bras. PI. Med., Botucatu, v.15, n.1, p.13-24, 2013. 
família Apocynaceae. Os resultados dos testes histoquímicos indicam que as estruturas secretoras estão envolvidas com a produção de compostos fenólicos, látex e polissacarídeos. Estudos específicos são necessários para evidenciar o papel desses compostos na planta, bem como para caracterizar o seu perfil fitoquímico e possível potencial para fins fitoterapêuticos.

\section{AGRADECIMENTOS}

Ao Prof. Dr. André Olmos Simões da Universidade Estadual de Campinas pela determinação do material botânico.

\section{REFERÊNCIA}

AGUIAR, S.; CARMELLO-GUERREIRO, S. M.; KINOSHITA, L. S. Ontogenia e estrutura do pericarpo de Prestonia riedelii (Mull. Arg.) Markgr. (Apocynaceae). Acta Botanica Brasilica, v. 23, p. 1-8, 2009.

APPEZZATO-DA-GLÓRIA, B.; ESTELITA, M.E.M. Laticifers systems in Mandevilla illustris and $M$. velutina (Apocynaceae). Acta Societatis Botanicorum Poloniae, v.66, p.301-6. 1997.

APPEZZATO-DA-GLÓRIA, B.; ESTELITA-TEXEIRA, M.EM. Anatomia do sistema aéreo vegetativo de Mandevilla pohliana (Stadelm.) A. Gentry (Apocynaceae). Hoehnea, v. 19, p. 39-50, 1992.

APPEZZATO-DA-GLÓRIA, B.; ESTELITA, M.E.M. Development, structure and distribution of colleters in Mandevilla illustris and M. velutina (Apocynaceae). Revista Brasileira de Botânica, v. 23, p.113-120, 2000. BRUNETON, J. Pharmacognosy: phytochemistry medicinal plants. $2^{\text {nd }}$ ed. Hampshire: Intercept, 1999. 1119p.

CAIN, A.J. The use of Nile Blue in the examination of lipids. Quarterly Journal of Microscopical Science, v. 88, p. 383-392, 1947.

CLARK, G. Staining procedures. $3^{\text {rd }}$ ed. Baltimore, The Williams \& Wilkins, 1973. 422p.

CASTRO, M.M.; DEMARCO, D. Phenolic compounds produced by secretory structures in plants: a brief review. Natural Product Communications, v. 3, p. 1205-1376, 2008.

DEMARCO, D. Estruturas secretoras florais e coléteres foliares em espécies de cerrado de Aspidosperma Mart. e Blepharodon Decne (Apocynaceae s.I.) 2005. 125p. Dissertação (Mestrado - Biologia Vegetal) - Departamento de Botânica. Universidade Estadual de Campinas, Campinas.

DEMARCO, D.; KINOSHITA, L.S.; CASTRO, M. M. Laticíferos articulados anastomosados - novos registros para Apocynaceae. Revista Brasileira de Botânica, v. 29, p. 133-144, 2006.

ENDRESS, M.E.; BRUYNS, P.V. A revised classification of Apocynaceae s.l. Botanical Review, v. 66, p. 1-56, 2000. FALLEN, M.E. Floral structure in the Apocynaceae: morphological, functional and evolutionary aspects. Botaniche Jahrbücher für Systematik, v. 106, p. 245286,1986 .
FAHN, A. Secretory Tissues in Plants. London: Academic Press, 1979. 302p.

FAHN, A. Plant Anatomy. Oxford: Pergamon Press, 1990. 559p.

FISHER, D.B. Protein staining of ribboned epon sections for light microscopy. Histochemie, v. 16, p. 92-6, 1968.

FJELL, I. Anatomy of the xeromorphic leaves of Allamanda neriifolia, Thevetia peruviana and Vinca minor (Apocynaceae). Nordic Journal of Botany, v. 3, p. 383392, 1983.

FURR, M.; MAHLBERG, P.G. Histochemical analyses of lacticifers and glandular trichomes in Cannabis sativa. Journal of Natural Products, v. 44, p. 153-9, 1981.

GALETTO, L. Flower structure and nectar chemical composition in three Argentine Apocynaceae. Flora, v. 192, p. 127-207, 1997.

GARDNER, R.O. Vanillin-hydrochloric acid as a histochemical test for tannin. Stain Technology, v. 50, p. 315-7, 1975.

GERLARCH, D. Botanische mikrotechnik: Eine Einführung. Stuttgart: Georg Thieme, 1969. 321p.

GOMES, S.M.; KINOSHITA, L.S.; CASTRO, M. M. Hemisincarpia e nectário apendicular enfocados através de ontogênese floral em Macrosiphonia velame Müll. Arg., Apocynoideae. Revista Brasileira de Botânica, v. 31, p. 81-93, 2008.

GREGORY, M; BAAS, P. A survey of mucilage cells in vegetative organs of the dicotyledons. Israel Journal of Botany, v. 38, p. 125-174. 1989

HIGH, O.B. Lipids histochemistry. New York: Oxford University Press, 1948. 281p.

INAMDAR, J.A.; MURUGAN, V.; SUBRAMANIAN, R.B. Ultrastructure of non-articulated laticifers in Allamanda violacea. Annals of Botany, v 62, p. 583-588, 1988.

JOHANSEN, D.A. Plant microtechnique. New York: McGraw-Hill, 1940. 523p.

JOLY, A.B. Botânica. Introdução à taxonomia vegetal. $4^{a}$ Ed. São Paulo, Companhia Editora Nacional, 1977. 777p. JUDD, W.; CAMPBELL, C.S.; KELLOGG, E.A.; STEVENS, P.E. Plant Systematics, a phylogenetic approach. Sunderland: Sinauer Associates, 2002. 464p.

KAY, Q.O.N.; DAOUD, H.D. \& STIRTON, C.H. Pigment distribution, light reflection and cell structure in petals. Botanical Journal of Linnean Society, v. 83, p. 57-84, 1981.

LERSTEN, N.R. Morphology and distribution of colleters and crystals in relation to the taxonomy and bacterial leaf nodule symbiosis of Psychotria (Rubiaceae). American Journal of Botany, v. 61, p. 973-981, 1974.

LIN, S. \& BERNARDELLO, G. Flower structure and reproductive biology in Aspidorperma quebracho-blanco (Apocynaceae), a tree pollinated by deceit. International Journal of Plant Sciences, v. 60, p. 869-878, 1999.

LOPES, K. L. B.; THADEO, M.; AZEVEDO, A. A.; SOARES, A. A.; MEIRA, R. M. S. A. Articulated laticifers in the vegetative organs of Mandevilla atroviolacea (Apocynaceae, Apocynoideae). Botany, v. 87, p. 202209, 2009.

MAHLBERG, P.G. Embriogeny and histogenesis in Nerium oleander. II. Origin and development of the nonarticulated laticifers. American Journal of Botany, v. 48, p. 90-9, 1963. MAHLBERG, P.G. Laticifers: an historical perspective. Botanical Review, v. 59, p. 1-23, 1993. 
MARIMUTHU, S. Chemotaxonomy of Apocynaceae. Journal of Plant Anatomy and Morphology, v. 5, p. 15-20, 1988.

MARTINS, F.M. Leaf and calycine colleters in Odontadenia lutea (Apocynaceae Apocynoideae Odontadenieae): their structure and histochemistry. Brazilian Journal of Botany, v. 35, p. 59-69, 2012.

MARTINS, F.M.; KINOSHITA, L.; CASTRO, M.M. Coléteres foliares e calicinais de Temnadenia violacea (Vell.) Miers (Apocynaceae, Apocynoideae): estrutura e distribuição. Revista Brasileira de Botânica, v. 33, p. 519-530, 2010.

MCMANUS, J.F.A. Histological and histochemical uses of periodic acid. Stain Technology, v. 23, p. 99-108, 1948. METCALFE, C.R.; CHALK, L. Anatomy of the dicotyledons: leaves, stem and wood in relation to taxonomy with notes on economic uses. Oxford: Clarendon Press, 1950. v.1, 560p.

MILANEZ, F.R. Ontogênese dos laticíferos contínuos de Nerium oleander. In: XXVI CONGRESSO NACIONAL DE BOTÂNICA, 1975, Rio de Janeiro. Anais. Rio de Janeiro: Editora da UFRJ, 1977. 343-379.

OLIVEIRA, F.; AKISSUE, G. Fundamentos da Farmacobotânica. São Paulo, Livraria Atheneu, 1989. $221 \mathrm{p}$.

PEARSE, A.G.E. Histochemistry: theorical and applied. Edinburgh: Livingstone, 1985. v. 2, 249p.

PIZZOLATO, T.D. Staining of Tilia mucilages with Mayer's tannic acid-ferric chloride. Bulletin of the Torrey Botanical Club, v. 104, p. 277-9, 1977.

PIZZOLATO, T.D.; LILLIE, R.D. Mayer's tannic acid-ferric chloride stain for mucins. Journal of Histochemistry and Cytochemistry, v. 21, p. 56-64, 1973.

RAO, V.S.; GANGULI, A. Studies in the floral anatomy of the Apocynaceae. Journal of the Indian Botanical Society, v. 42, p. 419-435, 1963.

RIET-CORREA, F.; MENDEZ, M. C. \& SCHILD, A. L. Intoxicação por plantas e micotoxicoses em animais domésticos. Porto Alegre, Hemisfério Sul do Brasil, 1993. 340p.

RIO, M.C.S.; Castro, M.M.; Kinoshita, L.S. Distribuição e caracterização anatômica dos coléteres foliares de Prestonia coliata (Vell.) Woodson (Apocynaceae). Revista Brasileira de Botânica, v. 25, p. 339-349, 2002.

RIO, M.C.S.; KINOSHITA, L.S.; Castro, M.M. Anatomia foliar como subsídio para taxonomia das espécies de Forsteronia G.Mey. (Apocynaceae) dos cerrados paulistas. Revista Brasileira de Botânica, v. 28, p. 713-726, 2005. SACCHETTI, G.; BALLERO, M; SERAFINI, M.; ROMAGNOLI, C.; BRUNI, A.; POLI, F. Laticifer tissue distribution and alkaloid location in Vinca sadoa (Apocynaceae), and endemic plant of Sardinia (Italy). Phyton, v. 39, p. 265-275, 1999.
SAKANE, M.; SHEPHERD, G.J. Uma revisão do gênero Allamanda L. (Apocynaceae). Revista Brasileira de Botânica, v. 9, p. 125-149, 1986.

SIMÕES, A.O. Estudos filogenéticos e anatômicos da tribo Mesechiteae Miers (Apocynaceae, Apocynoideae). 2004. 175p. Tese (Doutorado - Biologia Vegetal) - Departamento de Botânica. Universidade Estadual de Campinas, Campinas.

SIMÕES, A.O.; CASTRO, M.M.; Kinoshita, L.S. Calycine colleters of seven species of Apocynaceae (Apocynoideae) from Brazil. Botanical Journal of the Linnean Society, v. 152, p. 387-398, 2006.

SIMÕES, C.M.O.; SCHENKEL, E.P.; GOSMANN, G.; MELLO, J.C.P.; MENTZ, L.A.; PETROVICK, P. Farmacognosia: da planta ao medicamento. $5^{\mathrm{a}} \mathrm{Ed}$. Florianópolis: Editora da UFSC, 2004. 833p.

SOLEREDER, H. Systematic anatomy of the dicotyledons.v1. Oxford: Clarendon Press, 1908. 1182p. SOUZA, V.C.; LORENZI, H. Botânica sistemática. Nova Odessa, Instituto Plantarum, 2005. 703p.

THOMAS, V. Structural, functional and phylogenetic aspects of the colleter. Annals of Botany, v. 68, p. 287305, 1991.

THOMAS, V.; DAVE, Y. Histochemistry and senescence of colleter of Allamanda cathartica L. (Apocynaceae). Annals of Botany, v. 64, p. 201-3, 1989.

THOMPSON, J.D.; MEINWALD, J.; ANESHANSELY, D.; EISNER, T. Flavonols: pigments responsible for ultraviolet absorption in nectar guide of flower. Science, v. 177, p. 528-530, 1972.

TORRES, C.; GALETTO, L. Patterns and implications of floral nectar secretion, chemical composition, removal effects and standing crop in Mandevilla pentlandiana (Apocynaceae). Botanical Journal of the Linnean Society, v. 127, p. 207-223, 1998.

VALENTE, M.C. Matelea maritima subsp. gangliosa (Vell.) Font. Anatomia Vegetal (Asclepiadaceae). Arquivos do Jardim Botânico do Rio de Janeiro v. 34, p. 145-176, 1996.

VALENTE, M.C.; COSTA, C.G. Estudo anatômico da flor de Marsdenia loniceroidees E. Fournier (Asclepiadoideae - Apocynaceae). Rodriguésia v. 56, p. 51-66, 2005.

WILSON, K.J.; MAHLBERG, P.G. Ultrastructure of nonarticulated laticifers in mature embryos and seedlings of Asclepias syriaca L. (Asclepiadaceae). American Journal of Botany, v. 65, p. 98-109, 1978.

WILSON, K.J.; MAXAN, T.E. Ultrastructure of articulated laticifers in Stapelia bella (Asclepiadaceae). American Journal of Botany v. 74, p. 628-638, 1987.

WOODSON, R.E.; MOORE, J.A. The vascular anatomy and comparative morphology of apocynaceous flowers. Bulletin of the Torrey Botanical Club, v. 65 , p. 135$165,1938$. 